Research Article

\title{
Study of the pattern of adverse events following immunization of children in a tertiary care hospital
}

\author{
Rekha Y. Aherkar*, Pradeep K. Deshpande, Balasaheb B. Ghongane
}

Department of Pharmacology, B. J. Government Medical College \& Sassoon General Hospital, Pune, Maharashtra, India

Received: 22 April 2016 Accepted: 26 April 2016

*Correspondence to:

Dr. Rekha Y. Aherkar,

Email: drrekhaaherkar10

@gmail.com

Copyright: (C) the author(s), publisher and licensee Medip Academy. This is an openaccess article distributed under the terms of the Creative Commons Attribution NonCommercial License, which permits unrestricted noncommercial use, distribution, and reproduction in any medium, provided the original work is properly cited.

\begin{abstract}
Background: Success of an immunization programme depends upon awareness regarding usefulness and safety of vaccines. Widespread information on vaccine safety is very essential. Objective of study was to analyze pattern of Adverse Events Following Immunization (AEFI) in children.

Methods: Prospective, observational study was carried out at immunization OPD of B. J. Government Medical College and Sassoon General hospital, Pune, where children receiving routine immunization were analyzed $\&$ followed up through telephonic survey of parents. Vaccine Adverse Event Reporting System (VAERS) form was used to record AEFI.

Results: Total 1206 children, aged 0-6 years, received total of 3179 vaccine doses. 22.71\% AEFI were reported. Most common AEFI per 1000 doses of all vaccinations was Fever, seen in less than 9 months of age group (84.67\%). DPT vaccine was most common vaccine associated with AEFI and maximum (37.8\%) adverse events were seen with 1 st dose of DPT.

Conclusions: Reporting of AEFI with regular analysis and feedback should be an integral part of immunization programs.
\end{abstract}

Keywords: Active surveillance, Vaccine safety, Vaccine surveillance, VAERS

\section{INTRODUCTION}

The Universal Immunization Programme (UIP) of India is amongst the largest immunization programmes in the world, targeting 27 million infants and 30 million pregnant women. ${ }^{1}$ Vaccine pharmacovigilance is the science and activities relating to the detection, assessment, understanding and communication of Adverse Event Following Immunization (AEFI) and other vaccine or immunization-related issues, and to the prevention of untoward effects of the vaccine or immunization. $^{2}$ Like other pharmaceutical products, vaccines also carry risk of adverse events. But expectations with regard to vaccine safety are high, as they are administered to healthy individuals. Because of increase in vaccine coverage and additional booster doses, the risk of an adverse event is proportionally increased. Paradoxically, an effective immunization programme will result in decrease in incidence rates of the target diseases, but might also result in an increase in adverse events. ${ }^{3}$

Pharmacovigilance on vaccines in India is still in infantile stage. ${ }^{4,5}$ A strong system for reporting vaccine adverse events (Vaccine Adverse Event Reporting SystemVAERS) exists in most developed countries including the US. ${ }^{6}$ Though AEFI surveillance in India started along with the UIP in 1985, the AEFI reporting remained suboptimal for long time in the country. ${ }^{7}$ A constant flow of complete information on vaccine adverse events is necessary. As only a few Indian studies on adverse events of vaccines could be traced, there is a need of 
pharmacovigilance of vaccines on a large scale in India. The present study aimed to collect data on AEFI and to do active search of adverse events in pediatric population.

\section{METHODS}

This study was a prospective, observational, single center, six month (15 December 2013 to 15 June 2014) duration. The study protocol was approved by the Institutional Ethics committee. The study was conducted in B. J. Government Medical College and Sassoon general hospital, Pune where total 1206 children aged 0 to 6 years, attending the immunization outpatient department (OPD) were recruited. Children received Oral Polio Vaccine (OPV), Diphtheria-Tetanus- Pertussis (DPT), Hepatitis B, Measles vaccines, and Bacillus Calmette Guerin vaccine (BCG) as per the National Immunization Schedule. To maintain uniformity and identity, DPT was injected in left thigh, Hepatitis B vaccine in right thigh, Measles vaccine in right arm and BCG vaccine in left arm. The study protocol was explained in detail to the parents of children. All the parents willing to participate in the study were asked to fill an informed consent form. A Case Record Form was designed to obtain basic information like demographic data, vaccine details including batch number, manufacturing date, expiry date, manufacturing company etc. (Table 1) Subjects with immune compromised state, allergic reactions, convulsions or other neurological disorder, failure to provide consent were excluded from study. A telephonic survey of parents or guardians was conducted twice, consisting of an initial call on $7^{\text {th }}$ day and a second call on $30^{\text {th }}$ days after the vaccine administration date. The parents of children were questioned about the appearance of any type of reaction that has followed administration of the vaccine. The parents/guardians of children were also given telephone number of the investigator so that they can contact in case of any problem following vaccine administration.

Table 1: Vaccine details.

\begin{tabular}{|c|c|c|c|}
\hline Batch no. & Manufacturing company & Manufacturing date & Expiry date \\
\hline \multicolumn{4}{|l|}{ OPV } \\
\hline P160213 & Bio-med private limited & 2013 Feb & 2015 Jan \\
\hline Q285 & Bio-med private limited & 2013 April & 2015 March \\
\hline P210913 & Bio-med private limited & 2013 Sep. & 2015 Aug \\
\hline 63AS14013 & Bharat biotech & 2014 Jan & 2015 Dec \\
\hline \multicolumn{4}{|l|}{ DPT } \\
\hline TAG05B/13 & Human biological institute & 2013 June & 2015 May \\
\hline 3A2646 & Human biological institute & 2013 May & 2015 April \\
\hline TAG05A/13 & Human biological institute & 2013 June & 2015 may \\
\hline TAG11B/13 & Human biological institute & 2013 July & 2015 June \\
\hline TAG48A/13 & Human biological institute & 2013 Dec & 2015 Nov \\
\hline \multicolumn{4}{|l|}{ Hepatitis B } \\
\hline 51AD13020 & Bharat biotech & 2013 April & 2016 March \\
\hline 51AD13027 & Bharat biotech & 2013 May & 2016 April \\
\hline HBV 43/13 & Human biological institute & 2013 Nov & 2016 Oct \\
\hline \multicolumn{4}{|l|}{ Measles } \\
\hline $003 F 2244$ & Serum Institute of India & 2012 Dec & 2014 Nov \\
\hline 003F2213A & Serum Institute of India & 2012 Nov & 2014 Oct \\
\hline $003 \mathrm{~N} 2171 \mathrm{~A}$ & Serum Institute of India & 2012 Sep & 2014 Aug \\
\hline \multicolumn{4}{|l|}{ BCG } \\
\hline L037 & BCG vaccine laboratory Chennai & 2012 May & 2014 April \\
\hline GSV-014/13 & Green Signal Bio Pharma Pvt. Ltd. & 2013 Sep & 2015 Aug \\
\hline
\end{tabular}

The Vaccine Adverse Events Reporting System Forms (VAERS) form was used to record the adverse events following vaccination. ${ }^{8}$ All demographic data, adverse event description and vaccine details including batch number, manufacturer, route, previous doses was entered promptly, in accordance with specific instructions accompanying the VAERS Form. Naranjo Adverse Drug Reaction Probability Scale form (Naranjo score) was used and type of adverse events were divided as definite, probable, possible and doubtful. ${ }^{9}$ Children with the complaint of Adverse Event were called back to hospital, examined for AEFI and appropriate treatment was given by pediatrician. Sudden onset adverse events are considered as those which occur within 24 hours of vaccine administration while, delayed adverse events occurred after 24 hours of vaccine administration. The 
detailed data was entered into the Microsoft excel sheet and subsequently analyzed statistically by using Microsoft excel 2013.

\section{RESULTS}

A total of 1206 children were included in study during 6 month data collection period. Amongst them 610 $(50.58 \%)$ were male and $596(49.41 \%)$ were female. 0 to 6 year aged children received OPV, DPT, Hepatitis-B, measles and BCG vaccines according to immunization schedule followed in hospital. Total 274 adverse events were reported. Gender distribution of AEFI is shown in Figure 1.

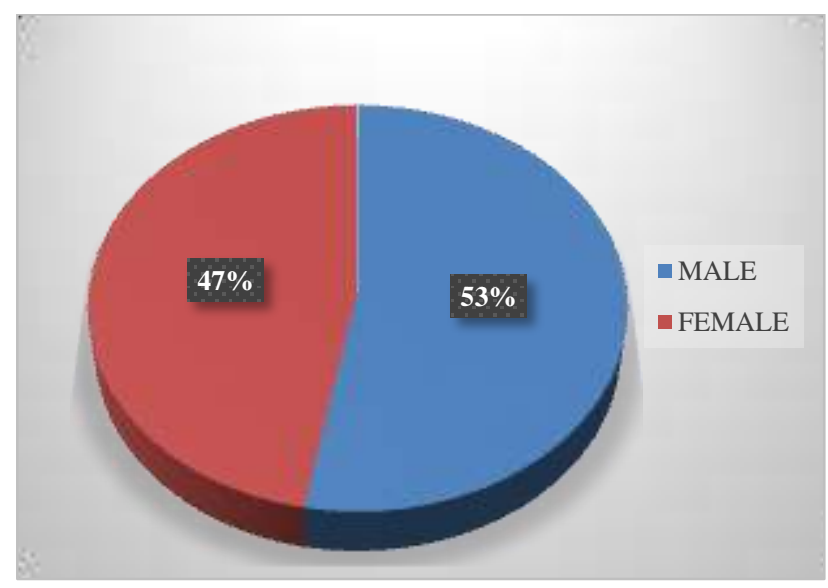

Figure 1: Gender distribution of adverse events.

As mentioned in Table 2, most of the adverse events were seen in age group of less than 9 months of age (232 out of 274 i.e. $84.67 \%$ ). In sub group analysis children of 1.5 2.5 month age group had maximum (80) adverse events. Total vaccine doses administered were 3179 (1022 were oral, 2157 were injectable vaccines). Distribution of vaccines is shown in Figure 2. It shows that OPV doses were given to maximum children 1022, followed by Diphtheria-Tetanus- pertussis vaccine doses (978) and Hepatitis-B vaccine doses (766). Total 340 Measles vaccine doses and 73 BCG vaccine doses were administered.

Table 2: Age wise distribution of adverse events during follow up.

\begin{tabular}{|llll|}
\hline $\begin{array}{l}\text { Age } \\
\text { (months) }\end{array}$ & $\begin{array}{l}\text { Number of } \\
\text { AEFI on } 7^{\text {th }} \\
\text { day follow up }\end{array}$ & $\begin{array}{l}\text { Number of } \\
\text { AEFI on } \text { 30 }^{\text {th }} \\
\text { day follow up }\end{array}$ & $\begin{array}{l}\text { Number of } \\
\text { vaccinated } \\
\text { children }\end{array}$ \\
\hline $0.01-<1.5$ & 19 & 0 & 53 \\
\hline $1.5-<2.5$ & 77 & 3 & 244 \\
\hline $2.5-<3.5$ & 62 & 2 & 193 \\
\hline $3.5-<9$ & 68 & 1 & 278 \\
\hline $9-<18$ & 11 & 1 & 193 \\
\hline $18-<60$ & 22 & 0 & 179 \\
\hline $60-72$ & 8 & 0 & 66 \\
\hline Total & 267 & 7 & 1206 \\
\hline
\end{tabular}

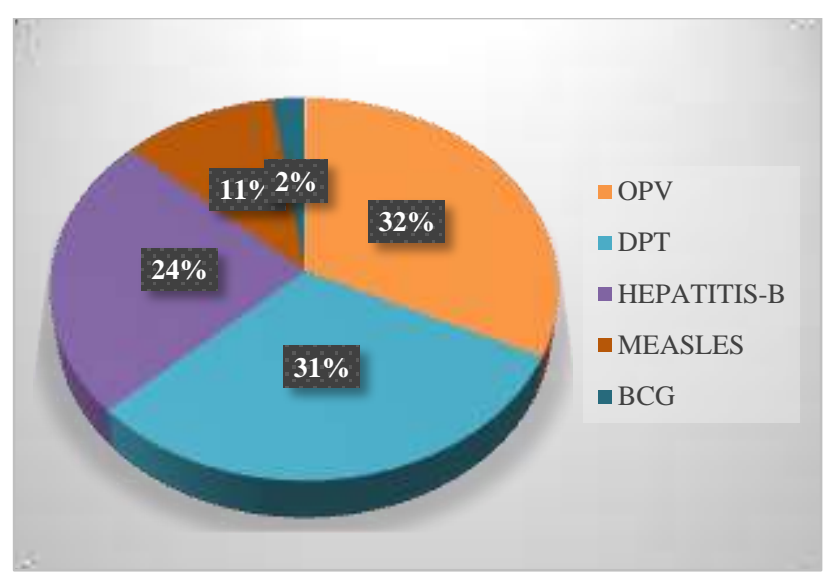

Figure 2: Distribution of vaccine doses in children.

Out of 1206 children, 35 children were given 4 vaccines at a time, 881 children were given 3 vaccines, 106 children were given 2 vaccines and 184 children were given 1 vaccine. Incidence rate of AEFI was calculated as ratio of total number of children suspected to have at least one AEFI to total number of children recruited in study multiplied by 100 . Out of 1206 children, there were 269 children who were observed to have at least one AEFI. Hence, the incidence of AEFI was 22.3\%. Out of 269 children 5 had got adverse events in both the follow ups. Hence total 274 AEFI were reported out of a total of 3179 vaccine doses given. So the rate of AEFI per thousand vaccine doses was 86.19 .

Table 3: Adverse event pattern per 1000 vaccine doses.

\begin{tabular}{|lll|}
\hline $\begin{array}{l}\text { Name of adverse } \\
\text { event }\end{array}$ & $\begin{array}{l}\text { Number of } \\
\text { AE reported }\end{array}$ & $\begin{array}{l}\text { Rate per 1000 } \\
\text { doses of all } \\
\text { vaccinations }\end{array}$ \\
\hline Fever & 173 & 54.41 \\
\hline Diarrhoea & 20 & 6.29 \\
\hline Excessive crying & 8 & 2.51 \\
\hline Running nose & 1 & 0.31 \\
\hline \multicolumn{3}{|c|}{ Injection site reactions } \\
\hline $\begin{array}{l}\text { Swelling at } \\
\text { injection site }\end{array}$ & 75 & 34.77 \\
\hline $\begin{array}{l}\text { Nodule at } \\
\text { injection site }\end{array}$ & 7 & 3.24 \\
\hline $\begin{array}{l}\text { Pain at injection } \\
\text { site }\end{array}$ & 4 & 1.85 \\
\hline $\begin{array}{l}\text { Abscess at } \\
\text { injection site }\end{array}$ & 3 & 0.46 \\
\hline $\begin{array}{l}\text { Redness at } \\
\text { injection site }\end{array}$ & 1 \\
\hline $\begin{array}{l}\text { Total } \\
\text { \$Total doses of vaccine administered (n=3179) is the } \\
\text { denominator for all except for 'swelling, redness, nodule, pain at } \\
\text { injection site' and 'abscess at injection site' for which only the } \\
\text { number of vaccines which were administered by injection } \\
\text { (n=2157) is taken as denominator. More than one adverse event }\end{array}$ \\
\begin{tabular}{l} 
was counted separately in this table. \\
\hline
\end{tabular}
\end{tabular}


As mentioned in Table 3. Most common AEFI per 1000 doses of all vaccinations was Fever (54.41) followed by swelling at injection site (34.3). Table 4 shows various patterns of adverse events like fever, injection site reactions, diarrhoea and excessive crying etc. Most common adverse event observed was fever, followed by injection site reaction in both male and female (Table 5). Some children had more than one co existing adverse event, the most frequently occurring of which was the presence of Fever and Swelling at left thigh. Fever with other reaction category constituted fever with any other co-existing adverse event like running nose or pain at injection site or swelling at injection site or excessive crying. Injection site reaction constituted swelling or nodule or abscess or redness or pain at injection site.

Table 4: Pattern of adverse events and responsible vaccine.

\begin{tabular}{|c|c|c|c|c|c|}
\hline Type of AEFI & OPV & DPT & Hep-B & Measles & BCG \\
\hline Fever & & $6+144^{*}$ & $141^{*}$ & $2+14^{*}$ & $2+15^{*}$ \\
\hline Diarrhoea & 20 & & & & \\
\hline Excessive crying & & $7^{*}$ & $7^{*}$ & $1^{*}$ & $1^{*}$ \\
\hline Running nose & & $1^{*}$ & $1^{*}$ & & \\
\hline \multicolumn{6}{|c|}{ Injection site reactions } \\
\hline Swelling at injection site & & 71 & & 4 & \\
\hline Nodule at injection site & & 6 & & 1 & \\
\hline Pain at injection site & & 4 & 1 & 2 & \\
\hline Redness at injection site & & 1 & & & \\
\hline Abscess at injection site & & & & & 3 \\
\hline
\end{tabular}

Table 5: Pattern of adverse events among male and female.

\begin{tabular}{|lll|}
\hline Type of adverse event & Male & Female \\
\hline Fever & 89 & 74 \\
\hline Swelling at left thigh & 27 & 33 \\
\hline Diarrhoea & 12 & 8 \\
\hline Swelling at left thigh and excessive cry & 3 & 0 \\
\hline Fever \& Swelling at left thigh & 2 & 4 \\
\hline $\begin{array}{l}\text { Measles vaccine injection site swelling } \\
\text { at right arm }\end{array}$ & 2 & 2 \\
\hline Injection site abscess & 2 & 1 \\
\hline $\begin{array}{l}\text { Nodule of approximately 2 cm } \\
\text { diameter at injection site of DPT }\end{array}$ & 2 & 1 \\
\hline $\begin{array}{l}\text { Nodule of approximately 2-3 cm } \\
\text { diameter at injection site of DPT }\end{array}$ & 1 & 2 \\
\hline Fever \& running nose & 1 & 0 \\
\hline Fever with excessive crying & 1 & 0 \\
\hline Fever with pain at injection site & 1 & 0 \\
\hline $\begin{array}{l}\text { Swelling \& pain at left thigh, excessive } \\
\text { crying }\end{array}$ & 1 & 0 \\
\hline Excessive crying & 1 & 0 \\
\hline $\begin{array}{l}\text { Fever with excessive crying, } \\
\text { Pain at injection site }\end{array}$ & 0 & 1 \\
\hline $\begin{array}{l}\text { Pain at injection site with excessive } \\
\text { crying }\end{array}$ & 0 & 1 \\
\hline $\begin{array}{l}\text { Swelling at left thigh \& redness at } \\
\text { injection site }\end{array}$ & 0 & 1 \\
\hline $\begin{array}{l}\text { Nodule of approximately 2.5 cm } \\
\text { diameter at injection site of measles }\end{array}$ & 0 & 1 \\
\hline Total & 145 & 129 \\
\hline
\end{tabular}

It was observed that maximum $(37.8 \%)$ adverse events were seen with 1 st dose of DPT vaccine \& number decreased in subsequent doses (Figure 3). All adverse events were mild to moderate in nature. None of the severe adverse event was observed in this study. Sudden onset events constituted $70.07 \%$ (192 out of 274) of total AEFI while 29.93\% (82 out of 274) AEFI were Delayed type (Figure 4). Causality assessment as per Naranjo scale showed that $98.18 \%$ (269 out of 274) of AEFI were probable and $1.82 \%$ (5 out of 274) of AEFI were possible.

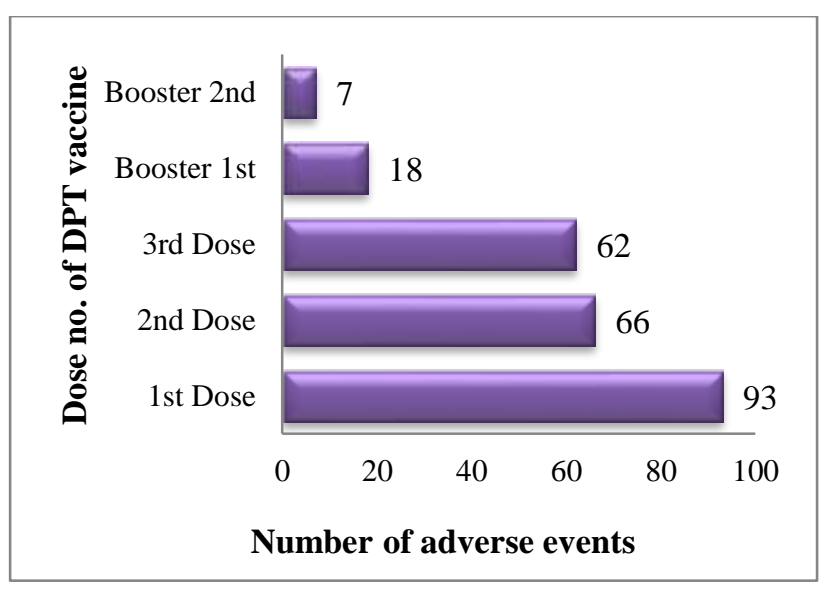

Figure 3: Number of adverse events with DPT vaccine. 


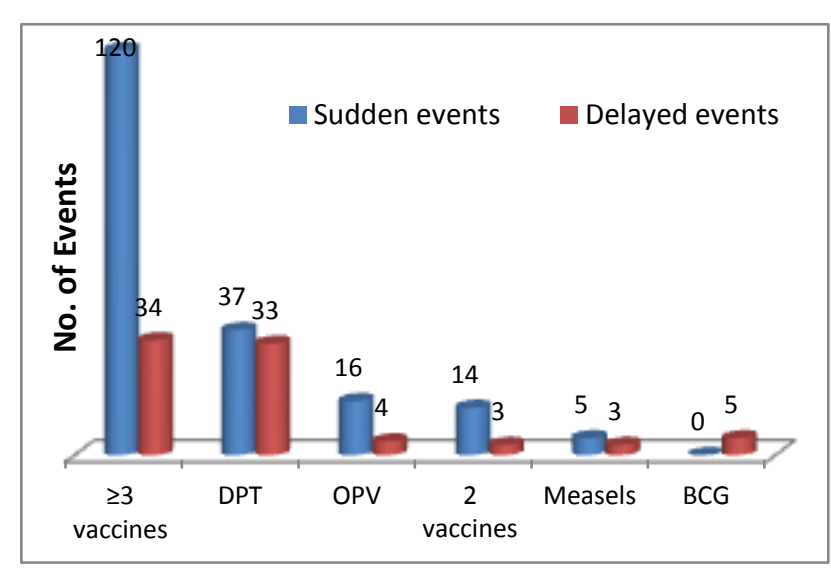

Figure 4: Sudden and delayed onset adverse events.

\section{DISCUSSION}

India has one of the largest Universal Immunization Programs in the world in terms of the number of vaccines used, number of beneficiaries covered and human resources involved. Objectives of AEFI surveillance in country are to monitor immunization safety, detect and respond to adverse events following immunization and also to correct hazardous immunization practices. So the final outcome will lead to reduction of the negative impact of the events on health and improvement of quality of immunization. Vaccine's post licensure surveillance is an essential part of an immunization program which continuously monitors the safety of routinely used vaccines. ${ }^{10}$

The present study was performed to assess the pattern of adverse events following OPV, DPT, Hepatitis-B, Measles and BCG vaccines administration. Various studies have been conducted in different countries as a part of their national surveillance programmes.

The methodology of present study was similar to study done by Joshi $\mathrm{N}$ et al. 2013 in India ${ }^{11}$ and CarrascoGarrido et al. 2004 in Spain $^{12}$ for 6 months duration. Many other studies related to vaccine adverse events surveillance have used vaccine adverse reporting system data or other vaccine data links. These studies were retrospective unlike present study which is prospective.

The majority of AEFI were from the age group of less than 1 year in the present study. This could be because most of the vaccine doses were administered at this age according to the National Immunization Programme. The incidence of AEFI in present study population is $22.3 \%$ which is nearer to a study by Joshi et al. 2013 where incidence was found to be $20.8 \%$ and Carrasco-Garrido et al. 2004 in Spain which reported about 19\% AEFI. ${ }^{11,12}$

In current study, the most common adverse event was fever. Zhou et $\mathrm{al}^{13}$ in US and Joshi et $\mathrm{al}^{11}$ in India also found fever as most common adverse event. The study by $\mathrm{Hu}$ et $\mathrm{al}^{14}$ in China and Zhang LP et al ${ }^{15}$ also stated that most frequently reported AEFI was fever followed by injection site reaction and allergic reaction. A study by Carrasco-Garrido et $\mathrm{al}^{12}$ in Spain and by Mansoor et $\mathrm{al}^{16}$ in New Zealand mentioned swelling at the site of injection as the most common AEFI. Vaccines containing aluminium salts as adjuvant, such as diphtheria and tetanus vaccines can cause injection site reactions. ${ }^{17}$ Improper injection technique may increase the risk of local reactions. Hence, proper vaccination technique and cleaning the injection site reduce further complications. ${ }^{18}$ DPT was the vaccine showing the highest AEFI and still is the vaccine with the highest occurrence of AEFI in young children. ${ }^{19}$ DPT vaccine induced injection site swelling may differ according to site of vaccine administration. The incidence of swelling is more when the vaccine is administered on arm than on thigh. ${ }^{20}$ It was observed that adverse events after first dose of DPT were more and number decreased after subsequent doses. ${ }^{21}$ The probable mechanisms for development of adverse events may include live viral activity, injection-related direct needle trauma or reactions, immune-mediated reactions and cytokine production. ${ }^{22}$ One study in Japan quoted diarrhoea as a minor adverse event after oral polio vaccine administration. ${ }^{23}$

Joshi $\mathrm{N}$ et al found AEFI rate 99.2 per 1000 vaccine doses while present study reveals AEFI to be 86.19 per 1000 vaccine doses. The overall average annual reporting rate of AEFI from Zhejiang province in China was 9.2 per 100,000 doses through passive surveillance. This study used National AEFI surveillance system data base and 19 different vaccine's adverse events in all age groups. ${ }^{14}$ An overall reporting rate in Australia in 2009 was 11.2 per 100,000 doses in less than 1 year old population and included 33 vaccines in study also through passive surveillance. ${ }^{19}$ This variation in rates of reported AEFI in different countries could be explained by type of surveillance, type of vaccines under study, variable case definitions, reporting criteria and variable compliance with reporting.

Anaphylactic or acute hypersensitivity reactions may be life-threatening. One must look for such sudden onset reaction and all emergency medicines should be kept ready before hand. Though such anaphylactic reactions were not reported in this study, this possibility should always be kept in mind while administering injectable vaccines. Also equal attention must be paid towards delayed onset reactions as their early detection and prompt treatment may avoid further complications.

The present study has some limitations like study duration is short and follow up is by telephonic calls. The minor ailments may not be reported. This study was performed in tertiary care hospital setup hence outcome of this study may not be applicable to population vaccinated at primary health centers, private hospitals and in camp by nongovernment organizations. Systemic planned, prospective, large scale study is needed for definitive outcomes. 


\section{CONCLUSION}

An active search system for adverse events to vaccines is a good method for detecting and quantifying mild adverse events that are usually missed by passive surveillance. However, situations such as under-reporting or difficulty in finding a causal association between the appearance of the adverse events and the administration of the vaccine tend to hamper pharmacovigilance. Vaccines have sideeffects, but none of them are as severe as the diseases themselves. The benefits of immunization in preventing disease significantly outweigh the risks of immunizationrelated adverse events. This study revealed that all adverse events were mild to moderate in nature. Thus after identifying the vaccines responsible for adverse events and the characteristics of the events; one may continue to consider vaccines as safe biological products.

On-going surveillance of AEFI and regular analysis and reporting of these data should be integral in the management of immunization programs. The improved AEFI surveillance and reporting system in India should go in a long way to increase and preserve the faith of the community in the existing and new vaccines and increasing the immunization coverage in India. All AEFI should be noted and reported to Central Drug Standard Control Organization so that database will be generated regarding vaccine use and awareness of vaccine safety.

Funding: No funding sources

Conflict of interest: None declared

Ethical approval: The study was approved by the Institutional Ethics Committee

\section{REFERENCES}

1. National Vaccine Policy, New Delhi, Government of India, Ministry of Health and Family Welfare, 2011. Available

http://mohfw.nic.in/WriteReadData/1892s/10848111 97NATIONAL\%20VACCINE\%20POLICY\%20BO OK.pdf Accessed on 18 Oct 2015.

2. World Health Organization. Causality assessment of adverse event following immunization (AEFI): user manual for the revised WHO classification. 2013. Available

at http://apps.who.int/iris/bitstream/10665/80670/1/978 9241505338_eng.pdf?ua=1 Accessed on 15 Oct 2015.

3. Waldman EA. Surveillance of adverse effects following vaccination and safety of immunization programs. Rev Saude Publica. 2011;45(1):1-11.

4. Budhiraja $\mathbf{S}$. Pharmacovigilance in vaccine. Indian $\mathbf{J}$ Pharmacol. 2010;42(2):116-9.

5. Karande S, Gogtay NJ, Kshirsagar NA. Efficacy and safety of vaccines in Indian children: a review. Paediatric and Perinatal Drug Therapy. 2003;5(3):124-34.

6. Vaccine Adverse Event Reporting System (VAERS): About VAERS program (FAQ).
Available at http://vaers.hhs.gov/about/faqs. Accessed on 3 Jan 2014.

7. Chitkara AJ, Thacker N, Vashishtha VM, Bansal CP, Gupta SG. Adverse Event Following Immunization (AEFI) surveillance in India: position paper of Indian Academy of Pediatrics, 2013. Indian Pediatr. 2013;50:739-41.

8. CDC, Food and Drug Administration. Vaccine Adverse Event Reporting System. VAERS Form. Available https://vaers.hhs.gov/resources/vaers_form.pdf Accessed on 27 Sep 2015.

9. Naranjo CA, Busto U, Sellars EM, Sandor P, Ruiz I, Roberts EA, et al. A method for estimating the probability of adverse drug reactions. Clin Pharmacol Ther. 1981;30:239-45.

10. Universal immunization program: Ministry of Health and Family Welfare. Government of India. $2009 . \quad$ Available at http://mohfw.nic.in/WriteReadData/1892s/Immuniza tion_UIP.pdf. Accessed on 17 Sep 2014.

11. Joshi ND, Prajapati HK, Solanki KC, Sukhlecha A, Trivedi HR, Gajera MV, et al. Pattern of adverse events following immunization in an Indian teaching hospital. IJMSPH. 2013;2(1):62-8.

12. Carrasco-Garrido P, Gallardo-Pino C, JiménezGarcía R, Tapias MA, de Miguel AG. Incidence of adverse reactions to vaccines in a paediatric population. Clin Drug Invest. 2004;24(8):457-63.

13. Zhou W, Pool V, John K, English-Bullard R, Ball R, Wise RP, et al. Surveillance for safety after immunization: Vaccine Adverse Event Reporting System (VAERS): United States, 1991-2001. MMWR Surveill Summ. 2003;52(1):1-24.

14. Hu Y, Li Q, Lin L, Chen E, Chen Y, Qi X, et al Surveillance for Adverse Events following Immunization from 2008 to 2011 in Zhejiang Province, China. Clin Vaccin Immunol. 2013;20(2):211-7.

15. Zhang LP, Yu F, Jin BF, Wang Y, Xu HL, DU Y. Surveillance of adverse events following immunization in Minhang district of Shanghai from 2007 to 2010. Zhonghua $\mathrm{Er} \mathrm{Ke} \mathrm{Za} \mathrm{Zhi.}$ 2012;50(11):859-64.

16. Mansoor O, Pillans PI. Vaccine adverse events reported in New Zealand 1990-5. N Z Med J. 1997;110(1048):270-2.

17. Israeli E. Gulf war syndrome as a part of the autoimmune (auto inflammatory) syndrome induced by adjuvant (ASIA) Lupus. 2012;21(2):190-4.

18. Stephan F, McLisa VD. Vaccine administration Preventing serious shoulder injuries. J Am Pharm Assoc. 2013;53(2):102-3.

19. Mahajan D, Roomiani I, Gold M, Lawrence G, McIntyre P, Menzies R. et al. Annual report: surveillance of adverse events following immunization in Australia, 2009. Commun Dis Intell. 2010;34(3):259-76.

20. Jackson LA, Peterson D, Nelson JC, Marcy SM, Naleway AL. Vaccination site and risk of local 
reactions in children 1 through 6 years of age. Pediatrics. 2013;131(2):283-9.

21. Monteiro SAM, Takano OA, Waldman EA. Evaluation of the Brazilian surveillance system for adverse events following vaccination. Revista Brasileira de Epidemiologia. 2011;14(3):361-71.

22. Poland GA, Ovsyannikova IG, Jacobson RM. Adversomics: the emerging field of vaccine adverse event immunogenetics. Pediatr Infect Dis J. 2009;28(5):431-32.

23. Sugawara T, Ohkusa Y, Taya K, Yasui Y, Wada N, Sakano M, et al. Diarrhoea as a minor adverse effect due to oral polio vaccine. Jpn $\mathrm{J}$ Infect Dis. 2009;62:51-3.

Cite this article as: Aherkar RY, Deshpande PK, Ghongane BB. Study of the pattern of adverse events following immunization of children in a tertiary care hospital. Int J Basic Clin Pharmacol 2016;5:609-15. 